\title{
Prevalência das doenças de pele não neoplásicas em cães no município de Cuiabá, Mato Grosso ${ }^{1}$
}

INDEX TERMS: Diseases of dogs, skin diseases, dermatology, dermatohistopathology.

RESUMO.- 0 objetivo deste trabalho foi avaliar as principais doenças de pele não neoplásicas em cães atendidos no Hospital Veterinário da Universidade Federal de Mato Grosso no ano de 2011. Nesse período, 112 casos dermatológicos foram atendidos, dos quais sistematicamente realizou-se biópsia de pele. Em 93,7\% foi possível estabelecer o diagnóstico definitivo por meio de análise histopatológica junto a métodos diagnósticos complementares. As doenças cutâneas de maior prevalência eram de origem parasitária, imunológica, bacteriana e fúngica. Nesses grupos,

\footnotetext{
${ }^{1}$ Recebido em 21 de setembro de 2012.

Aceito para publicação em 6 de dezembro de 2012.

${ }^{2}$ Programa de Pós-Graduação em Ciências Veterinárias (PPGVet), Faculdade de Agronomia, Medicina Veterinária e Zootecnia (FAMEV), Universidade Federal de Mato Grosso (UFMT), Av. Fernando Corrêa da Costa 2367, Bairro Boa Esperança, Cuiabá, MT 78068-900, Brasil.

${ }^{3}$ Bolsista de Iniciação Científica do CNPq junto a Faculdade de Agronomia, FAMEV-UFMT, Cuiabá, MT.

${ }^{4}$ Departamento de Clínica Médica Veterinária (Climev), FAMEV-UFMT, Cuiabá, MT. *Autor para correspondência: regia@ufmt.br

${ }^{5}$ Programa de Pós-Graduação em Pesquisa Clínica em Doenças Infecciosas, Instituto de Pesquisa Evandro Chagas da Fundação Oswaldo Cruz, Av. Brasil 4.365, Manguinhos, RJ 21040-360, Brasil.
}

as afecções cutâneas que mais ocorreram foram a demodicidose $(20,9 \%)$, a leishmaniose visceral $(12,4 \%)$, a atopia $(10,5 \%)$, a dermatofitose $(10,5 \%)$ e a piodermite superficial disseminada $(8,6 \%)$. Essas cinco condições perfizeram juntas, pouco mais da metade de todas as doenças de pele de cães diagnosticadas neste estudo.

TERMOS DE INDEXAÇÃO: Doenças de cães, doenças de pele, dermatologia, dermatohistopatologia.

\section{INTRODUÇÃO}

A dermatologia é uma área que gradativamente ganha importância na medicina veterinária. Estima-se que entre $20 \%$ e $75 \%$ dos atendimentos veterinários realizados em clínicas e hospitais estão diretamente relacionados às doenças de pele. Essa alta prevalência ocorre pelo fato de que a pele pode refletir processos patológicos que são primários ou compartilhados com outros tecidos (Scott, Miller \& Griffin 1996). Além disso, as alterações de pele são facilmente visíveis e fazem com que o proprietário procure auxílio veterinário mais imediato (Souza et al. 2006).

Uma anamnese detalhada e um exame físico minucioso, junto a métodos diagnósticos rotineiros como raspados de 
pele, exame micológico direto, tricograma, exame citológico e cultura fúngica e bacteriana são importantes para se estabelecer o diagnóstico final ou os diagnósticos diferenciais em dermatologia. No entanto, esses exames complementares podem não ser suficientes para o diagnóstico e nesses casos o clínico deve recorrer ao exame histopatológico sempre que possível (Conceição et al. 2004).

A dermatopatologia permite a visualização da morfologia dos tecidos e seus resultados adicionam informações importantes sobre a condição dermatológica do paciente, mesmo em casos em que não se pode chegar a um diagnóstico final (Werner 2008). Entretanto, a metodologia de diagnóstico histopatológico por padrões de lesão, que foi introduzida pela primeira vez na dermatopatologia humana por Ackerman (1978) e adaptada à medicina veterinária (Gross et al. 1992), vem sendo utilizada de forma particularmente útil para o diagnóstico das doenças inflamatórias de pele (Scott et al. 1996, Werner 2008).

Com base na casuística, o estudo das doenças de pele se torna cada vez mais importante para os clínicos e dermatopatologistas de pequenos animais, pois embora a literatura sobre dermatologia seja vasta, há pouca informação disponível sobre a ocorrência das principais doenças de pele de acordo com as diferentes regiões geográficas do país. Além disso, os poucos estudos epidemiológicos existentes são na grande maioria internacionais (Sischo et al. 1989, Scott \& Paradis 1990, Hill et al. 2006) e podem não refletir a situação nacional.

Este artigo visa determinar a prevalência das doenças de pele não neoplásicas que comprometem cães atendidos no Hospital Veterinário da Universidade Federal de Mato Grosso (Hovet-UFMT) no ano de 2011, a fim de direcionar o diagnóstico clínico dermatológico canino.

\section{MATERIAL E MÉTODOS}

Selecionou-se entre os meses de abril a dezembro de 2011, durante o atendimento clínico no Hovet-UFMT, 112 cães com queixa principal de doenças de pele não neoplásica. Para anotar dados relativos ao histórico, exame físico e exames clínicos complementares necessários para a confirmação ou exclusão diagnóstica, elaborou-se uma ficha dermatológica. Durante o exame clínico foram estabelecidas suspeitas diagnósticas baseadas nos padrões lesionais macroscópicos (Scott et al. 1996, Ginn et al. 2007) e amostras foram enviadas para exames complementares como bacteriológico, micológico, parasitológico, citológico e tricograma. Sistematicamente, realizou-se biópsia de pele de todos os cães selecionados. Com punch $3 \mathrm{~mm}$, após anestesia local subcutânea com lidocaína 2,0\%, foram retirados fragmentos de três áreas diferentes de lesão. As amostras foram fixadas em solução de formalina a $10 \%$, processadas rotineiramente para histologia e coradas pela hematoxilina-eosina (HE). Em alguns casos, colorações especiais específicas foram realizadas como método auxiliar para a conclusão diagnóstica (Prophet et al. 1992). As doenças de pele diagnosticadas foram categorizadas em 1) parasitárias; 2) imunológicas; 3) bacterianas; 4) fúngicas; 5) endócrinas; 6) hereditárias; 7) psicogênicas; 8) adquiridas; e 9) defeitos da ceratinização. As dermatopatias que não foram classificadas em nenhum desses tópicos foram agrupadas sob a expressão "outras dermatopatias". Casos em que não foi possível se chegar a um diagnóstico foram agrupados como inconclusivos.

\section{RESULTADOS}

No setor de clínica médica do Hovet-UFMT, 112 cães foram examinados devido a algum distúrbio dermatológico não neoplásico. Dos 112 cães, 59 (52,7\%) eram machos e 53 $(47,3 \%)$ eram fêmeas. Setenta e nove cães $(70,5 \%)$ eram de raça pura e $33(29,5 \%)$ não tinham raça definida. As raças mais prevalentes incluíram Pit Bull (16/112 [14,3\%]), Poodle (10/112 [8,9\%]), Pinscher (7/112 [6,2\%]), Boxer $(6 / 112[5,3 \%])$, Rottweiler (5/112 [4,5\%]), Shih-tzu $(4 / 112[3,6 \%])$, Labrador $(4 / 112[3,6 \%])$, Yorkshire (4/112 [3,6\%]), Teckel (4/112 [3,6\%]), Cocker Spaniel (3/112 [2,7\%]), Bull Terrier (3/112 [2,7\%]) e Lhasa Apso $(3 / 112[2,7 \%])$. 0 restante dos $10(8,9 \%)$ cães de raça pura pertenciam a outras oito raças diferentes. A maior parte dos cães tinham entre 1 e 5 anos (52/112 [46,4\%]), segui-

Quadro 1. Distribuição dos diagnósticos conclusivos de acordo com as diferentes categorias de doenças cutâneas não neoplásicas em cães assistidos no Hovet-UFMT, em 2011

\begin{tabular}{lccccc}
\hline \multicolumn{1}{c}{ Diagnósticos } & $\begin{array}{c}\text { Total } \\
\text { (n) }\end{array}$ & $\%$ & Diagnósticos & $\begin{array}{c}\text { Total } \\
\text { (n) }\end{array}$ & $\%$ \\
\hline Dermatopatias parasitárias & 37 & 35,2 & Dermatopatias endócrinas & 5 & 4,80 \\
Demodicidose & 22 & 20,9 & Hipotireoidismo & 3 & 2,90 \\
Leishmaniose visceral & 13 & 12,4 & Hiperadrenocorticismo & 2 & 1,90 \\
Escabiose & 2 & 1,90 & Dermatopatias hereditárias & 5 & 4,80 \\
Dermatopatias imunológicas & 22 & 20,9 & Alopecia por diluição da cor & 3 & 2,90 \\
Atopia & 11 & 10,5 & Seborreia primária & 1 & 0,95 \\
Dermatite alérgica a picada de ectoparasitos & 5 & 4,80 & Calvice padrão & 1 & 0,95 \\
Erupção alérgica urticariforme & 4 & 3,80 & Dermatopatias psicogênicas & 2 & 1,90 \\
Dermatite alérgica pós-tosa & 1 & 0,95 & Dermatite acral por lambedura & 2 & 1,90 \\
Pustulose eosinofílica estéril & 1 & 0,95 & Dermatopatias adquiridas & 1 & 0,95 \\
Dermatopatias bacterianas & 16 & 15,2 & Alopecia por reação a injeção & 1 & 0,95 \\
Piodermite superficial disseminada & 9 & 8,60 & Defeitos da ceratinização & 1 & 0,95 \\
Vasculite séptica & 2 & 1,90 & Dermatite seborreica & 1 & 0,95 \\
Foliculite piotraumática & 2 & 1,90 & Outras dermatopatias & 3 & 2,85 \\
Foliculite e furunculose profunda & 1 & 0,95 & Adenite sebácea & 1 & 0,95 \\
Piodermite mucocutânea & 1 & 0,95 & Nódulo fibropruriginoso & 1 & 0,95 \\
Piodermite do pastor alemão & 1 & 0,95 & Dermatite hiperplásica crônica & 1 & 0,95 \\
Dermatopatias fúngicas & 13 & 12,4 & & & 105 \\
Dermatofitose & 11 & 10,5 & & 100,0
\end{tabular}


do pelos mais jovens, com idade entre zero e 1 ano (29/112 $[25,9 \%])$. Os cães mais velhos, com idade entre 5 e 10 anos totalizaram 19,6\% (22/112). Cães com 10 anos ou mais totalizaram 8\% (9/112) da população afetada.

Dos 112 cães atendidos com queixa de doenças de pele não neoplásica, 93,7\% (105) foram agrupados dentro de uma categoria diagnóstica e $7(6,3 \%)$ foram considerados inconclusivos. Em relação à origem das diferentes categorias de doenças, a ocorrência foi a seguinte: parasitárias (37/105 [35,2\%]), imunológicas $(22 / 105$ [20,9\%]), bacterianas $(16 / 105[15,2 \%])$, fúngicas $(13 / 105[12,4 \%])$, endócrinas $(5 / 105[4,8 \%])$, hereditárias $(5 / 105[4,8 \%])$, psicogênicas $(2 / 105[1,9 \%])$, adquiridas $(1 / 105[0,95 \%])$, defeitos da ceratinização $(1 / 105$ [0,95\%]) e outras dermatopatias $(3 / 105[2,8 \%])$. Instituiu-se diagnóstico morfológico não específico com base nas lesões histopatológicas para os casos inconclusivos. A distribuição dos diagnósticos conclusivos de acordo com as diferentes categorias de doenças cutâneas de cães está no Quadro 1.

\section{DISCUSSÃO}

Neste trabalho foi possível estabelecer o grupo diagnóstico em 93,7\% dos casos avaliados. Esses resultados são semelhantes aos descritos por outros autores (Hill et al. 2006, Souza et al. 2009) e encorajam a utilização do "punch" $3 \mathrm{~mm}$ como uma opção de ferramenta para a biópsia de pele em lesões simples e planas, pois o tamanho reduzido dispensa pontos de sutura, trazendo maior conforto para o clínico, paciente e proprietário.

As dermatopatias parasitárias foram as mais prevalentes neste estudo e a demodicidose foi o principal diagnóstico etiológico verificado nesse grupo (22/105 [20,9\%]), demonstrando a importância da doença na região. Esses dados são contrários aos obtidos em estudos internacionais (Sischo et al. 1989, Scott \& Paradis 1990, Hill et al. 2006) e embora não se saiba o exato motivo pelo qual essa doença é tão comum em nosso meio, é possível que isso se deva, pelo menos em parte, ao fato de que no Brasil, embora a reprodução de cães que tiveram sarna demodécica seja desencorajada pelos veterinários, sabe-se que são poucos os proprietários e criadores que submetem seus cães à esterilização por esse motivo, o que acaba perpetuando linhagens familiares predispostas à doença (Willemse 1995, Scott et al. 1996, Souza et al. 2009). Além disso, a grande quantidade de cães com até 5 anos de idade pode ter favorecido essa alta prevalência de demodicidose, já que essa é uma doença que acomete principalmente animais jovens (Scott et al. 1996). Outro importante resultado neste trabalho e que parece não ser frequentemente verificado em outros estudos (Scott \& Paradis 1990, Hill et al. 2006, Souza et al. 2009, Cardoso et al. 2011) foi a ocorrência de leishmaniose visceral $(12,4 \%)$. Essa alta prevalência foi obtida provavelmente pelo fato de que este trabalho foi realizado em uma região endêmica para a enfermidade (Almeida et al. 2010). 0 estado de Mato Grosso possui clima tropical, com estação seca e chuvosa bem definida e temperatura elevada, fatores que favorecem a procriação do fleblotomíneo transmissor e viabilizam a disseminação da doença (Missawa \& Lima 2006).
A elevada ocorrência de doenças imunológicas (22/105 $[20,9])$ neste trabalho guarda semelhanças a outros estudos realizados em vários locais do mundo (Sischo et al. 1989, Scott \& Paradis 1990, Hill et al. 2006). Dados obtidos na região Sul do Brasil demonstraram que as doenças de pele imunológicas contribuem com $44 \%$ a $53 \%$ do total de diagnósticos estabelecidos (Machado 2004, Bianchi et al. 2008) e que grande parte desses casos são de dermatite alérgica a picada de pulga (DAPP). Esse achado difere com o que foi observado neste estudo, onde DAPP foi diagnosticada em apenas $4,8 \%$ dos casos de doenças imunológicas. Essa variação epidemiológica pode estar relacionada às diferenças climáticas que podem fazer da pulga um ectoparasita variavelmente prevalente de acordo com o grau de umidade e temperatura (Sischo, Ihrke \& Franti 1989). No presente trabalho, a atopia foi a principal causa de doença imunológica $(10,5 \%)$ e por ser uma afecção geneticamente programada, uma maior ocorrência tem sido observada em cães de raça pura (Farias 2007), fato confirmado neste estudo em que cães da raça Pit Bull representaram 36,4\% dos casos de atopia. A doença também ocorreu em cães das raças Poodle, Boxer, Bull Terrier, Yorkshire e Labrador. Embora predisposição sexual não tenha sido comprovada, descreve-se maior incidência de atopia em fêmeas (Scott, Miller \& Griffin 1996).

As doenças bacterianas foram a terceira maior causa de doença dermatológica nos cães avaliados e esse resultado difere de grande parte de outros estudos, que as apontam como as principais responsáveis pelas doenças de pele (Scott \& Paradis 1990, Hill et al. 2006, Cardoso et al. 2011). As infecções bacterianas são frequentemente descritas como causa secundária de afecções cutâneas (Scott et al. 1996) e o moderado índice obtido nesse estudo pode estar relacionado ao fato de que, para a categorização das doenças de pele, considerou-se a causa primária.

Dentro do grupo das doenças fúngicas, a dermatofitose correspondeu a $10,5 \%$ do total de diagnósticos estabelecidos no presente trabalho. Isso demonstra tanto semelhanças quanto diferenças com outros estudos em que alguns autores relatam frequências variando de $5 \%$ a $20 \%$, enquanto outros colocam a dermatofitose como uma doença cutânea com incidências variando entre $0,26 \%$ e 3,6\% (Lewis et al. 1991, Scott et al. 1996, Balda et al. 2004). Consciente desses dados conflitantes, além da ocorrência da lesão cutânea característica, exames de cultivo fúngico e histopatológico com resultados compatíveis foram necessários para firmar o diagnóstico de dermatofitose no intuito de descartar a possibilidade de diagnósticos equivocados, já que sabidamente outras doenças, tais como a foliculite estafilocócica, podem produzir lesões similares às descritas em casos de dermatofitose (Scott et al. 1996). Esse alto percentual concorda com a prevalência de dermatofitose em cães e gatos $(7,1 \%)$ obtida por Neves et al. (2011) em seu estudo retrospectivo nesta mesma região e esse fato provavelmente se deve às influências climáticas, visto que Cuiabá-MT possui predominantemente clima quente e úmido, o que viabiliza a ocorrência da doença (Scott et al. 1996).

0 baixo número de casos de doenças endócrinas neste trabalho pode estar relacionado ao número reduzido de 
cães senis atendidos, visto que cães mais velhos são mais susceptíveis ao desenvolvimento de algumas endocrinopatias, como hiperadrenocorticismo e hipotireoidismo (Halliwell 1990).

Dermatopatias hereditárias, psicogênicas, adquiridas, defeitos da ceratinização e outras dermatopatias perfizeram $11,4 \%$ do total de diagnósticos. A baixa ocorrência dessas doenças dermatológicas é semelhante à obtida por outros autores (Scott \& Paradis 1990, Hill et al. 2006, Souza et al. 2009, Cardoso et al. 2011).

\section{CONCLUSÕES}

Os resultados do presente estudo permitem concluir que doenças cutâneas parasitárias, imunológicas, bacterianas e fúngicas são as mais frequentemente diagnosticadas em cães no setor de clínica médica do Hovet-UFMT.

As afecções cutâneas de maior prevalência foram a demodicidose, leishmaniose visceral, atopia, dermatofitose e piodermite superficial.

Esse achado reforça a ideia corrente de que poucas doenças de pele são responsáveis pela maior parte dos atendimentos dermatológicos.

Agradecimentos.- À Coordenação de aperfeiçoamento de Pessoal de Nível Superior (CAPES) pela concessão de bolsa de mestrado. Ao Laboratório de Patologia Veterinária da Universidade Federal de Mato Grosso (LPV-UFMT) pelo auxílio no processamento e análise dos espécimes clínicos. Ao corpo clínico do Hospital Veterinário da Universidade Federal de Mato Grosso (Hovet-UFMT) pelo encaminhamento, após triagem, dos cães com doenças de pele não neoplásicas. Ao Laboratório de Microbiologia da Universidade Federal de Mato Grosso pelo auxílio com os exames micológicos.

\section{REFERÊNCIAS}

Ackerman A.B. 1978. Histologic Diagnosis of Inflammatory Skin Diseases: a method by pattern analyse. Lea and Febiger, Philadelphia. 863p.

Almeida A.B.P.F., Mendonça A.J. \& Sousa V.R.F. 2010. Prevalência e epidemiologia da leishmaniose visceral em cães e humanos, na cidade de Cuiabá, Mato Grosso, Brasil. Ciência Rural 40(7):1610-1615.

Balda A.L., Larsson C.E., Otsuka M. \& Gambale W. 2004. Estudo retrospectivo de casuística das dermatofitoses em cães e gatos atendidos no Serviço de Dermatologia da Faculdade de Medicina Veterinária e Zootecnia da USP. Acta Scient. Vet. 32(2):133-140.

Bianchi S.P., Correa R.K.R., Villa-Lobos W.O.R., Ferreira R.R. \& Machado M.L.S. 2008. Atendimentos realizados no ano de 2007 no Serviço de Dermatologia do Hospital de Clínicas Veterinárias da UFRGS. Anais 35o Conbravet, Gramado, RS, p.50.

Cardoso M.J.L., Machado L.H.A., Melussi M., Zamarian T.P., Carnielli C.M. \& Júnior J.C.M.F. 2011. Dermatopatias em cães: revisão de 257 casos. Arch. Vet. Sci. 16(2):66-74.
Conceição L.G., Loures F.H., Clemente J.T. \& Fabris V.E. 2004. Biópsia e histopatologia de pele: um valioso recurso diagnóstico na dermatologia. Revisão, Parte I. Clín. Vet. 51:36-44.

Farias M.R. 2007. Dermatite atópica canina: da fisiopatologia ao tratamento. Clín. Vet. 69:48-62.

Ginn P.E., Mansel J.E.K.L. \& Rakich P.M. 2007. Skin and appendages, p.553781. In: Maxie M.G. (Ed.), Jubb, Kennedy, and Palmer's Pathology of Domestic Animals. Vol.3. $5^{\text {th }}$ ed. Saunders Elsevier, Philadelphia.

Gross T.L., Ihrke P.J. \& Walder E.J. 1992. Veterinary dermatopathology: a macroscopic and microscopic evaluation of canine and feline skin disease. Mosby-Year Book. St Louis. 520p.

Halliwell R.E.W. 1990. Skin diseases of old dogs and cats. Vet. Rec. 126:389394.

Hill P.B., Lo A., Eden C.A.N., Huntley S., Morey V., Ramsey S., Richardson C., Smith D.J., Sutton C., Taylor M.D., Thorpe E., Tidmarsh R. \& Williams V. 2006. Survey of the prevalence, diagnosis and treatment of dermatological conditions in small animals in general practice. Vet. Rec. 158:533539.

Lewis D.T., Foil C.S. \& Hosgood G. 1991. Epidemiology and clinical features of dermatophytosis in dogs and cats at Louisiana State University: 19871990. Vet. Dermatol. 2(2):53-58.

Machado M.L.S., Appelt C.E. \& Ferreiro L. 2004. Dermatófitos e leveduras isolados da pele de cães com dermatopatias diversas. Acta Scient. Vet. $32: 225-232$

Missawa N.A. \& Lima G.B.M. 2006. Distribuição espacial de Lutzomyia longipalpis (Lutz et Neiva, 1912) e Lutzomyia cruzi (Mangabeira, 1938) no Estado de Mato Grosso. Revta Soc. Bras. Med. Trop. 39(4):337-340.

Neves R.C.S.M., Cruz F.A.C.S., Lima S.R., Torres M.M., Dutra V. \& Sousa V.R.F. 2011. Retrospectiva das dermatofitoses em cães e gatos atendidos no Hospital Veterinário da Universidade Federal de Mato Grosso, nos anos de 2006 a 2008. Ciência Rural 41(8):1405-1410.

Prophet E.B., Mills B., Arrington J.B. \& Sobin L.H. 1992. Laboratory Methods in Histotechnology. American Registry of Pathology, Armed Forces Institute of Pathology, Washington, DC. 279p.

Scott D.W. \& Paradis M. 1990. A survey of canine and feline skin disorders seen in a university practice: Small Animal Clinic, University of Montréal, Saint-Hyacinthe, Québec (1987-1988). Can. Vet. J. 31:830835.

Scott D.W., Miller W.H. \& Griffin C.E. 1996. Muller e Kirk - Dermatologia de Pequenos Animais. 5aㅡ ed. Interlivros, Rio de Janeiro. 1130p.

Sischo W.M., Ihrke P.J. \& Franti C.E. 1989. Regional distribution of ten commum skin diseases in dogs. J. Am. Vet. Med. Assoc. 195:752-756.

Souza T.M., Fighera R.A., Irigoyen L.F. \& Barros C.S.L. 2006. Estudo retrospectivo de 761 tumores cutâneos em cães. Ciência Rural 36:555-560.

Souza T.M., Fighera R.A., Schmidt C., Réquia A.H., Brum J.S., Martins T.B. \& Barros C.S.L. 2009. Prevalência das dermatopatias não-tumorais em cães do município de Santa Maria, Rio Grande do Sul (2005-2008). Pesq. Vet. Bras. 29(2):157-162.

Werner J. 2008. Padrões dermatohistopatológicos no diagnóstico dermatológico. Clín. Vet. 73:38-42.

Willemse T. 1995. Dermatologia Clínica de Cães e Gatos. 2ª ed. Manole, São Paulo. 141p. 